\title{
Specific genotypes of human papillomavirus in 125 high-grade squamous lesions and invasive cervical cancer cases from Congolese women
}

\author{
Luc Magloire Anicet Boumba ${ }^{1,2,3}$, Lahoucine Hilali², Mustapha Mouallif1,4, Donatien Moukassa ${ }^{3}$ \\ and Moulay Mustapha Ennaji ${ }^{1 *}$
}

\begin{abstract}
Background: Knowledge on HPV prevalence and genotype distribution in HSIL and ICC is highly essential for the introduction of an effective vaccination program and appropriate epidemiological monitoring of viral ecology before and after vaccination in Congo. This study aimed to determine the specific-HPV genotypes in HSIL and ICC among women in southwestern Congo.

Methods: 125 archival paraffin-embedded biopsy collected between 2008 and 2012 and histologically diagnosed were investigated. DNA extraction was performed using the phenol/chloroform method. HPV search was performed by nested-PCR using MY09/MY11 and GP5+/GP6+ consensus primers followed by direct sequencing.

Results: The mean age of participants was $44.3 \pm 8.2$ years. Overall, HPV prevalence was $89.6 \%(112 / 125)$ with all high-risk genotypes. HPV-DNA was detected in 81.5\% (53/65) of HSIL and 98.3\% (59/60) of ICC. HPV 16 the most common genotype was detected in $47.1 \%$ (25/53) of HSIL and 52.5\% (31/59) of ICC. Other types identified were: HPV 33 (22.6\%), HPV 18 (15\%), HPV 31 (11.3\%) and HPV 69 (3.7\%) in HSIL, and HPV 33 (28.8\%), HPV 18 (11.8\%), HPV 31 (5\%) and HPV 35 (1.7\%) in ICC. Knowing that the ADC accounted for 6.7\% (4/60) of ICC cases, HPV 18 was identified in 25\% (1/4) of these cases against 75\% (3/4) for HPV 16.
\end{abstract}

Conclusion: Our study showed that HPV 16, 33, 18 and 31 were the four most common genotypes in women with HSIL and ICC. These findings indicate that current vaccines against HPV could help to reduce the burden of cervical cancer in Congo.

Keywords: Specific-genotype, HPV, HSIL, ICC, Southwestern Congo

\section{Background}

Cervical cancer (CC) is a major public health problem worldwide. Invasive cervical cancer (ICC) is the third most common carcinoma among women in the world, representing $8.8 \%$ of all cancers. Worldwide 560,505 new cases of CC are predicted to occur by 2015 . More than 459,616 women aged less than 65 years will be affected. The number of deaths is estimated at 284902 women a year with 191,833 women aged less than 65 years [1].

In sub-Saharan Africa (SSA), 34.8 (around 75 141) new cases of cervical cancer are diagnosed per 100000 women

\footnotetext{
* Correspondence: m.ennaji@yahoo.fr

'Laboratoire de Virologie, Microbiologie et Qualité/ETB, Faculté des Sciences et Techniques, Université Hassan II Mohammedia, B.P. 146, Mohammedia 20650, Maroc

Full list of author information is available at the end of the article
}

annually, and 22.5 (around 50 233) per 100000 women die from the disease [1,2]. Rates of cervical cancer vary considerably in different sub-regions and are ranked first or second (after breast cancer) in all individual SSA countries. Guinea, Zambia, Tanzania, Malawi, and Mozambique have some of the highest ICC incidence rates in the world at $>50$ per100 000 women [2,3].

The Republic of Congo holds also some of the highest incidence and mortality rates of CC in SSA. The Agestandardized incidence rate is 25.2 per 100000 women (14.2 in the world and 30.6 in Central Africa). The Agestandardized mortality rate is 13.0 per 100000 women each year in the Congo (6.8 in the world and 22.2 in Central Africa) [4]. 
Human papillomavirus (HPV) infection has been identified as the primary cause of $\mathrm{CC}$ and the third most common cause of cancer-related death among women. HPV-DNA has been found in approximately $100 \%$ of CC cases [5]. Currently more than $150 \mathrm{HPV}$ are well characterized. Thereby, about 40 have a high tropism of anogenital tract. The International Agency for Research on Cancer [6] has defined twelve genotypes as high-risk (HR) oncogenic (HPV 16, 18, 31, 33, 35, 39, 45, 51, 52, 56, 58 , and 59), One probable oncogenic risk assigned to genotype 68 , and possible oncogenic risk assigned to the types: HPV 26, 53, 66, 67, 70, 73, 82, 30, 34, 69, 85, and 97. Low-risk (LR) genotypes that cause benign lesions and warts are (HPV 6, 11, 28, 32, 40, 42, 43, 44, 54, 55, 57, 61, $62,71,72,74,81,83,84,86,87$, and 89) $[1,7,8]$.

Although, most HPV infections are transient and disappear within 2 years without using any treatment [9], high-risk HPV types can cause persistent infection and are significantly associated with high-grade cervical lesions and cancer [10].

Moreover, two HPV vaccines have been developed, a bivalent for HPV-16 and HPV-18 and a quadrivalent for HPV-16, HPV-18, HPV-6 and HPV-11, capable of protecting in an effective way against an infection caused by these types [11,12]. Although, these vaccines also confer significant immunity against other HPV types, the efficiency of cross-protection is less than $100 \%$ $[13,14]$.

Although the distribution of high-risk types in Highgrade Squamous lesions (HSIL) and ICC shows little variation among regions of the world, [15-17], perfect knowledge of these types is essential for the introduction of an effective vaccination program and for better monitoring of viral ecology before and after vaccination in a less studied population. This information is also needed to assess the vaccine benefit on cervical cancer prevention in the population.

Until now, no study has been conducted on this target population in the Republic of Congo. Thus, the aim of this study was to determine the prevalence and the HPV type's distribution in HSIL and ICC among Congolese women in the southwestern part of the country.

\section{Methods}

\section{Sample collection}

One hundred and thirty six formalin-fixed paraffinembedded (FFPE) biopsy samples collected between 2008 and 2012 where HSIL and ICC diagnosis has been indicated were anonymously selected from tumor Registry files of Histopathological Unit of General Hospital of Loandjili (GHL) in Pointe-Noire. Altogether only 125 (91.9\%) archival FFPE samples were found, 65 HSIL and 60 ICC (including 56 invasive squamous cell carcinomas (SCC) and 4 adenocarcinoma (ADC)) from women aged
28-74 years (mean age: $44.3 \pm 8.2$ years). The mention of diagnosis and especially the availability of biopsy to the laboratory were the two major inclusion criteria. For the purposes of scientific research, the study was approved by the local ethics committee in the Health Sciences (Comité d'éthique de la Recherche en Sciences de la Santé, CERSSA) with an exemption from requiring consent from patients (study was carried out on archival material to be destroyed after a certain preservation time).

\section{DNA extraction}

Three to five sections of FFPE tissue were cut on a microtome and deparaffinized with xylenes and washed with $70 \%$ ethanol at ambient temperature. DNA extraction was performed using the manual technique of phenol/ chloroform used in the laboratory of Virology, Microbiology and Quality/Eco-toxicology and Biodiversity (LVMQ/ ETB) of the Faculty of Sciences and Techniques, University Hassan II Mohammedia-Casablanca in Morocco after enzymatic treatment with proteinase $\mathrm{K}$. The DNA was precipitated with $2 / 5$ volumes of $7.4 \mathrm{M}$ ammonium acetate and 2 volumes of $100 \%$ ethanol. DNA pellet was subsequently washed with $70 \%$ ethanol, air-dried and then suspended again in 30 or $50 \mathrm{~mL}$ of Ultra-pure PCR water nuclease-free (Bioline, UK), thereafter stored at $20^{\circ} \mathrm{C}$ until further use.

\section{HPV-DNA detection and genotyping}

After extraction, DNA concentration was evaluated in NanoDrop 8000 Spectrophotometer (Nanodrop Technologies, Wilmington, DE, USA). A 268-base-pair fragment of the housekeeping $\beta$-globin gene was amplified using the $\mathrm{GH} 20 / \mathrm{PCO} 4$ primer set to evaluate quality and integrity of DNA extract as previously described [18]. All amplifications were carried out with $100 \mathrm{ng} / \mu \mathrm{L}$ of DNA concentration in a Perkin Elmer 2400 GeneAmp PCR thermal Cycler (Scientific Support, Inc, Hayward, CA). DNA from the SiHa cell line was used as positive PCR control and Ultra-pure PCR water nuclease-free (Bioline, UK) as negative PCR control.

The samples were analyzed for HPV-DNA detection by nested-PCR using two consensus primer sets, i.e., MY09/MY11 and GP5/GP6 as previously described [19]. To avoid contamination leading to false positive results, both PCR round were performed in separate room. All primer sequences are given in Table 1. Amplified PCR product was analyzed on $2 \%$ agarose gel, stained with ethidium bromide and visualized under UV light. The PCR products were identified on the basis of their predicted fragment size. HPV typing was performed at the Molecular Biology and Functional Genomics platform of Support Unit Scientific Research and Technology, National Centre for Scientific and Technical Research of Rabat (UATRS-CNRST, Rabat, Morocco). Direct sequencing was 
Table 1 Primers used for HPV detection and typing in this study

\begin{tabular}{|c|c|c|c|c|}
\hline Primers & Sequences $\left(5^{\prime}\right.$ to $\left.3^{\prime}\right)$ & Target gene & Amplicons length & Ref \\
\hline $\mathrm{GH} 2 \mathrm{O}$ & GAA GAG CCA AGG ACA GGT AC & b-Globin & $268 \mathrm{pb}$ & Resnick et al., 1990 [18] \\
\hline PCO4 & CAA CTT CAT CCA CGT TCA CC & & & \\
\hline MYI 1 & GCM CAG GGW CAT AAY AAT GG & L1 & 450pb & Lee et al. 2009 [19] \\
\hline MYO9 & CGT CCM ARR GGA WAC TGA TC & & & \\
\hline GP5+ & TTT GTT ACT GTG GTA GAT ACT AC & L1 & $142 \mathrm{pb}$ & \\
\hline \multirow[t]{2}{*}{ GP6+ } & GAA AAA TAA ACT GTA AAT CAT ATT C & & & \\
\hline & $M=A+C, R=A+G, W=A+T, Y=C+T$ & & & \\
\hline
\end{tabular}

undertaken from the nested PCR product according to the BigDye Terminator v3.1 Cycle Sequencing Kit (PE/Applied Biosystems, Foster City, CA, USA) using the GP6+ antisense as primer. Purification of PCR products were carried out with the ExoSAP-IT ${ }^{\bullet}$ clean up system (USB Corporation, Cleveland, USA) whereas, the sequencing products was done with a Sephadex column 50G (Pharmacia Biotech Co., Ltd, Uppsala Sweden). Electrophoresis migration was performed in a 16 capillary automated sequencer 3131XL/Genetic HITACHI Analyzer (PE/Applied Biosystems, Foster City, CA, USA) at a constant voltage of $12 \mathrm{KV}$.

The DNA sequences were aligned by Molecular Evolutionary Genetics Analysis (MEGA) software Version 4.0 (http://www.megasoftware.net) and results were analyzed using the BLAST algorithm (http://www.ncbi.nih.gov/ BLAST). For each typing, we searched the hypervariable region from 34 to $50 \mathrm{bp}$ downstream of the GP5+ binding site (Figure 1) able to accurately identify any HPV genotypes as described previously [19]. An identity of $90 \%$ or more with the sequences of the GenBank database (NCBI, national Institute of Health, Bethesda, MD, USA) was retained to confirm every type of HPV obtained. The Nucleotide sequences data set supporting the results of this article was included within the article as additional file published through the LabArchives database (DIO “10.6070/H4PZ56TF”).

\section{Results}

\section{Overall HPV DNA prevalence}

Detection of HPV DNA was performed in tumor samples of 125 Congolese women with HSIL or ICC histologically diagnosed. Overall, DNA was successfully amplified in all of the $125(100 \%)$ samples tested ( $\beta$-globin PCR). Our results showed that $112 / 125(89.6 \%)$ of the total samples were positive for HPV-DNA. HPV-DNA was detected in 81.5\% (53/65) of HSIL and 98.3\% (59/60) of ICC (98.2\% of SCC and $100 \%$ of ADC respectively).

\section{HPV type-specific prevalence}

Six different genotypes have been identified, all were oncogenic high-risk types. HPV 16 the most common was detected in 47.1\% (25/53, 95\%IC: 34.4-60.3) of HSIL and $52.5 \%$ (31/59, 95\% IC: $40.0-64.7)$ of ICC. Other types identified were in decreasing frequency: HPV 33 (22.6\%, 95\%IC: 13.4-35.5), HPV 18 (15\%, 95\%IC: 7.8-27.0), HPV 31 (11.3\%) and HPV 69 (3.7\%) in HSIL; HPV 33 (28.8\%,

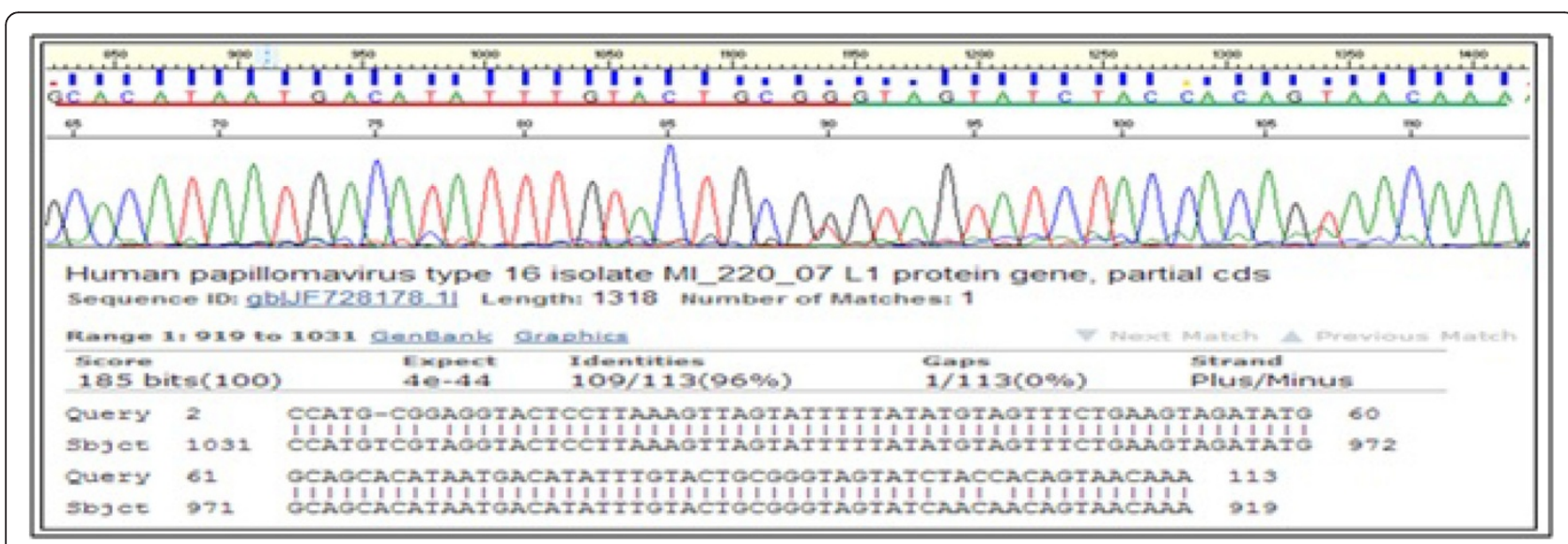

Figure 1 Sequencing data of HPV genotypes: An example of electrophoregram sequence from HPV type 16 and its Basic Local Alignment Search (BLAST) analysis result. Electrophoregram pointing the hyper variable region (underlined in red) of HPV L1 gene, downstream of the binding site of GP5+ primer (underlined in green, reading direction: from right to left). 
95\%IC: 18.8-41.4), HPV 18 (11.8\%, 95\%IC: 5.8-22.5), HPV $31(5 \%)$ and HPV 35 (1.7\%) in ICC.

Knowing that the ADC accounted for 6.7\% (4/59) of positive ICC cases, only 1 of out $4(1.7 \%)$ of them was identified as HPV 18 against 3 of out 4 (5\%) for HPV 16. All the results are reported in Table 2 and Figure 2.

The five most common individual oncogenic HPV types found in ICC in our study were compared with profiles found in the World, African regions; Europe and North America according to the WHO/ICO HPV information center (Table 3).

\section{Discussion}

The study reported here is the first of its kind among Congolese women with high-grade lesions and invasive cervical cancer in the aim of understanding the HPV prevalence and genotypes distribution in this target population groups in the southwestern part of the Country. Study was conducted retrospectively, using FFPE biopsies diagnosed as HSIL or ICC taken from 2008 to 2012, from GHL in Pointe-Noire. The GHL is the only hospital of south of the country to have a pathological laboratory. The Patients received in this laboratory come from different regions of the country and represents wide social and economic strata. Therefore, the results of our study could have particular interest in the area.

Worldwide, HPV prevalence in cervical cancer is reported to be $99.7 \%$ [5]. This prevalence is average $84.9 \%$ in HSIL and $87.2 \%$ in invasive cervical carcinoma [20]. In our study, $89.6 \%$ of the samples in general were HPV positive, of which $81.5 \%$ in HSIL and $98.3 \%$ in ICC. This findings corroborating with the literature data as reported in several countries especially in Africa where the prevalence is very high. Indeed, it was reported an average prevalence in Africa $85.1 \%$ and $93.9 \%$ in HSIL and ICC, respectively, with slight differences depending on the country [2,21]. Some countries such as Senegal, South Africa and Kenya have a prevalence of $80.9 \%$, 88.4\% and $96.6 \%$ in HSIL respectively. Mozambique, Kenya, and Morocco for their part have a prevalence of HPV infection in the ICC of the order of $97.7 \%, 96.9 \%$ and 94.7\% respectively [22,23]. But also in Europe [24], as shown a recent study in Italy reported a $96.0 \%$ rate of HPV positivity in the ICC [25].

In our study, HPV 16 was the most common genotype found in HSIL (47.1\%) and ICC (52.5\%). These findings let appear a very high proportion of the infection by this genotype in our study population and are in keeping with other studies in the world [26-28]. These data show that infection with HPV 16 is a great risk of cancer development and particular attention should be devoted to these cases $[29,30]$.

We found also HPV 33 was the second most common types in HSIL (22.6\%) and ICC (28.8\%) followed by HPV $18,15 \%$ and 11.8\%; HPV31, 11.3\% and 5\% in HSIL and ICC respectively. This profile although slightly different from those reported in sub-Saharan Africa $[20,31,32]$, generally reflects the global distribution pattern of HPV in Africa in some meta-analysis studies [16,33]. The type-specific distribution of HPV in799 cervical cancer biopsies from Africa showed that HPV 16 accounted for $50.2 \%$ of samples, HPV 18 for $14.1 \%$, and HPV 45 for $7.9 \%$ [34]. The cumulative prevalence of HPV 16/18 in our study was $62.1 \%(47.1 \% / 15 \%)$ and $64.3 \%(52.5 \% /$ $11.7 \%)$ in HSIL and ICC respectively. Our results are lower than the global average which is $70 \%$ for both types $[26,27]$. However, these results confirm the low prevalence of these two types combined in Africa compared to other regions of the world [16,28].

In his study of women with HIV in Pointe-noire, Alidjinou using the Hybrid Capture II (HC2) method had found a prevalence of $70.9 \%$ of combined HPV16/18/45 [35]. Knowing that the probe (probe HC2 16/18/45) used by the latter allowed only to make a global typing, these proportions would be comparable to ours if he had used a specific genotyping method especially as we have not found any HPV 45 in our study. However ours findings while corroborating with those reported in the literature shows that current prophylactic vaccines against HPV would play a significant role in reducing the burden of cervical cancer in Congo.

In addition, although often diagnosed in the ADC, on 4 cases of our study, only a case was positive by HPV 18. This result indicates that the genotype 16 remains dominant whatever the histological type of the cancer.

Table 2 Type-specific HPV and their distribution in paraffin-embedded biopsy specimens of HSIL and ICC cases from Congolese women, 2008-201

\begin{tabular}{|c|c|c|c|c|c|c|c|c|c|c|c|}
\hline \multirow[t]{2}{*}{ Histological types } & \multirow{2}{*}{$\begin{array}{l}\text { All HPV+ } \\
n(\%)\end{array}$} & \multicolumn{10}{|c|}{ HPV genotypes n (\%) } \\
\hline & & 16 & $95 \%$ IC & 33 & $95 \%$ IC & 18 & $95 \%$ IC & 31 & $95.1 \mathrm{C}$ & 69 & 35 \\
\hline HSIL $(n=65)$ & $53(81.5)$ & $25(47.1)$ & $34.4-60.3$ & $12(22.6)$ & $13.4-35.5$ & $8(15.0)$ & $7.8-27.0$ & $6(113)$ & $5.3-22.6$ & $2(3.7)$ & 0 \\
\hline $\operatorname{ICC}(n=60)$ & $59(98.3)$ & $31(52.5)$ & $40.0-64.7$ & $17(28.8)$ & 18.8.41.4 & $7(11.8)$ & $5.8-22.5$ & $3(5.0)$ & $1.7-13.9$ & 0 & $1(1.7)$ \\
\hline $\operatorname{SCC}(n=56)$ & $55(98.2)$ & $28(50.9)$ & $38.0-63.6$ & $17(30.9)$ & $20.3-44.0$ & $6(10.7)$ & $5.0-21.8$ & $3(5.3)$ & $1.8-14.8$ & 0 & $1(1.8)$ \\
\hline $\operatorname{ADC}(n=4)$ & $4(100)$ & $3(75.0)$ & $30.0-95.4$ & 0 & & $1(25.0)$ & $4.5-69.9$ & 0 & & 0 & 0 \\
\hline
\end{tabular}

$95 \% \mathrm{Cl}=$ confidence interval for the four most common genotypes identified. 


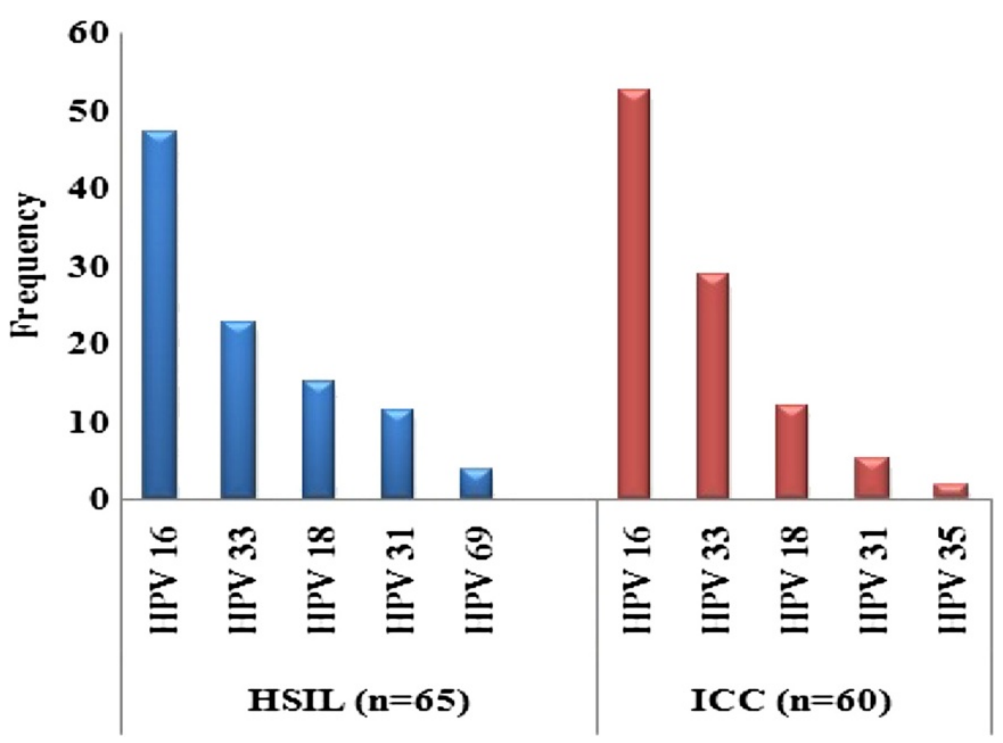

Figure 2 HPV genotypes frequencies in HSIL and ICC among women from southwestern Congo.

Frequently diagnosed among the first five genotypes in cervical cancer in the world, we found in our study a very high rate of HPV 33 in both HSIL (22.6\%) than in ICC (28.8\%), making it the second most prevalent type in our study population. This trend was also found with HPV 31 with frequencies of $11.3 \%$ and $5 \%$ in HSIL and ICC respectively. Admittedly lower degree, the high frequencies of these two types has been reported in several studies in Europe $[17,36]$. In our study, these results could be explained by the fact that the study area is open to a significant population mixing related to the industrial and oil activities. In the literature, it is reported the high proportion of $4 \%$ to $6 \%[17,37]$ of HPV35 in the ICC cases in SSA compared to another region in the world where the proportion is lower, ranging from $1 \%$ to $3 \%[16,21]$. In our study, 1 out of 60 cases was identified HPV-35 positive. Further studies with a larger sample are needed to assess the importance of this type in our population especially with the viral ecological change due to the vaccination against HPV 16/18. We also report the identification of
HPV 69 (3.7\%) in a relatively high proportion in HSIL but absent in the ICC. Although classified in the possible probable high risk types [1], its high proportion could reflect its oncogenic potential in cervix. An epidemiological surveillance would be necessary for this kind of genotype in our population after the introduction of vaccination against type 16 and 16 .

In sum, the pattern of distribution of HPV in HSIL and ICC in southwestern Congo is as follows: HPV16, HPV33, HPV18, HPV31, HPV69 and HPV35. Note the notable absence of HPV45 which is among the five frequently identified worldwide genotypes. Our study showed for the first time a high prevalence of HPV in HSIL and ICC in women attending GHL in Congo. Early detection of infection for high-risk types could give physicians the possibility of more effective management of the disease [38]. This study has also shown the distribution of HPV genotype in HSIL and ICC, reflecting the local epidemiology of HPV transmission in southwestern Congo populations. Thus; the burden of cervical cancer in our country

Table 3 The five most common HPV types among Congolese women with invasive cervical cancer in Southwestern Congo compared to the World, African regions, Europa and North America

\begin{tabular}{|c|c|c|c|c|c|c|c|}
\hline \multirow{2}{*}{$\begin{array}{c}\text { HPV } \\
\text { position }\end{array}$} & \multirow[t]{2}{*}{ Congo $^{a}$} & \multirow[t]{2}{*}{ World $^{\mathrm{b}}$} & \multicolumn{3}{|c|}{ Africa $^{b}$} & \multirow[t]{2}{*}{ Europa $^{b}$} & \multirow{2}{*}{$\begin{array}{c}\text { North } \\
\text { America }^{b}\end{array}$} \\
\hline & & & North Africa & South Africa & Western Africa & & \\
\hline $1^{\text {st }}$ & HPV16 (52.5\%) & HPV16 (56.7\%) & HPV16 (58.5\%) & HPV16 (52.1\%) & HPV16 (40.5\%) & HPV16 (58.8\%) & HPV16 (54.6\%) \\
\hline $2^{\text {nd }}$ & HPV33 (28.8\%) & HPV18 (15.9\%) & NPV18 (19.9\%) & HPV18 (10.7\%) & HPV45 (13.7\%) & HPV18 (16.3\%) & HPV18 (17.1\%) \\
\hline $3^{\text {nd }}$ & HPV18 (11.8\%) & HPV33 (4.6\%) & HPV45 (8.0\%) & HPV33 (9.1\%) & HPV18 (10.9\%) & HPV33 (4.4\%) & HPV31 (5.3\%) \\
\hline $4^{\text {th }}$ & HPV31 (5.0\%) & HPV45 (4.5\%) & HPV31 (2.5\%) & HPV31 (4.3\%) & HPV58 (3.9\%) & HPV45 (4.1\%) & HPV45 (4.7\%) \\
\hline $5^{\text {th }}$ & HPV35 (1.7\%) & HPV58 (4.4\%) & HPV33 (2.4\%) & HPV45 (3.3\%) & HPV33 (3.2\%) & HPV31 (4.1\%) & HPV33 (3.6\%) \\
\hline
\end{tabular}

(a) Data for Congo: present study.

(b) Source of information: WHO/ICO Information Centre on Human Papillomavirus (HPV) and Cervical Cancer [39]. 
must be supported by the implementation of primary prevention through vaccination but also a real organized cytology screening program.

\section{Conclusion}

The findings of this study are very significant because they provide, for the first time, baseline information on the HPV type's distribution in HSIL and ICC in the Republic of Congo, which may guide the development of CC prevention and control programs in the country. These findings also indicate that HPV vaccination might be beneficial among Congolese population.

\section{Competing interests}

The authors declare that they have no conflict of interests for this paper.

\section{Authors' contributions}

ALMB conducted all handling and the overall design of the experiment. MM participates in the writing and the critical reading of the manuscript. DM participated in the critical reading of the manuscript and sampling. $\mathrm{LH}$ and MME were responsible for the implementation of the project. All authors read and approved the final manuscript.

\section{Acknowledgements}

Authors gratefully acknowledge the Direction of General Hospital of Loandjili at Pointe-noire, Congo for having facilitated the transportation of samples to Morocco. We thank the functional genomics platform UATRS-CNRST Rabat, Morocco for sequencing. We also thank Dr. J. V. MAMBOU, Dr. Zineb Qmichou and Miss Raham Ait Hammou for their efforts in the critical reading of this article. This project was financially supported by the Moroccan Minister of Higher Education.

\section{Author details}

${ }^{1}$ Laboratoire de Virologie, Microbiologie et Qualité/ETB, Faculté des Sciences et Techniques, Université Hassan II Mohammedia, B.P. 146, Mohammedia 20650, Maroc. 'Laboratoire d'Agroalimentaire et Santé, Département de Biologie Appliquée, Faculté des Sciences et Techniques, Université Hassan 1er Settat, B.P. 577, Settat, Maroc. ${ }^{3}$ Laboratoire d'Analyses Médicales et Morphologiques, Hôpital Général de Loandjili, B.P. 8122, Pointe-Noire, Congo. ${ }^{4}$ Institut Supérieur des Sciences de la santé, Université Hassan 1er Settat, B.P. 577, Settat, Maroc.

Received: 9 August 2014 Accepted: 15 December 2014 Published: 23 December 2014

\section{References}

1. Ferlay J, Soerjomataram I, Ervik M, Dikshit R, Eser S, Mathers C, et al. GLOBOCAN 2012 v1.0, Cancer Incidence and Mortality Worldwide: IARC CancerBase No. 11 [Internet]. Lyon, France: International Agency for Research on Cancer; 2013. Available from http://globocan.iarc.fr.

2. De Vuyst H, Alemany L, Lacey C, Chibwesha CJ, Sahasrabuddhe V, Banura C, et al. The burden of human papillomavirus infections and related diseases in sub-saharan Africa. Vaccine. 2013;31 Suppl 5:F32-46.

3. Ferlay J, Shin HR, Bray F, Forman D, Mathers C, Parkin DM. Estimates of worldwide burden of cancer in 2008: GLOBOCAN 2008. Int J Canc. 2010;127 (12):2893-917

4. WHO/ICO. information centre on HPV and cervical cancer (HPV information center). Human Papillomavirus and related Deseases in Congo., Summary Report [17 june 2014]. 2014. http://www.hpvcentre.net/statistics/reports/COG.pdf.

5. Walboomers JM, Jacobs MV, Manos MM, Bosch FX, Kummer JA, Shah KV, et al. Human papillomavirus is a necessary cause of invasive cervical cancer worldwide. J Pathol. 1999;189:12-9.

6. IARC. Human Papillomaviruses. IARC Monographs on the Evaluation of Carcinogenic Risks to Humans Volume 100: A Review of Human Carcinogens Part B: Biological Agents. 2011. p. 261-319.

7. Schiffman M, Wentzensen N, Wacholder S, Kinney W, Gage JC, Castle PE. Human Papillomavirus Testing in the Prevention of Cervical Cancer. J Natl Cancer Inst. 2011;103:1-16.
8. Bouvard V, Baan R, Straif K, Grosse Y, Secretan B, El Ghissassi F, et al. A review of human carcinogens-Part B: biological agents. Lancet Oncol. 2009;10(4):321-2.

9. Ho GYF, Bierman R, Beardsley L, Chang CJ, Burk RD. Natural History of Cervicovaginal Papillomavirus Infection in Young Women. New England Journal of Medicine. 1998;338(7):423-8.

10. Rodríguez AC, Schiffman M, Herrero R, Hildesheim A, Bratti C, Sherman ME, et al. Longitudinal Study of Human Papillomavirus Persistence and Cervical Intraepithelial Neoplasia Grade 2/3: Critical Role of Duration of Infection. Journal of the National Cancer Institute. 2010;102(5):315-24. Available from http://jnci.oxfordjournals.org/content/102/5/315.abstract.

11. Teitelman AM, Stringer M, Averbuch T, Witkoski A. Human papillomavirus, current vaccines, and cervical cancer prevention. Journal of obstetric, gynecologic, and neonatal nursing : JOGNN / NAACOG. 2009;38(1):69-80.

12. Harper DM, Franco EL, Wheeler CM, Moscicki AB, Romanowski B, RoteliMartins CM, et al. Sustained efficacy up to 4.5 years of a bivalent L1 viruslike particle vaccine against human papillomavirus types 16 and 18: followup from a randomised control trial. Lancet. 2006;367(9518):1247-55.

13. Bornstein J. The HPV vaccines-which to prefer? Obstetrical \& gynecological survey. 2009;64(5):345-50.

14. Paavonen J, Jenkins D, Bosch FX, Naud P, Salmeron J, Wheeler CM, et al. Efficacy of a prophylactic adjuvanted bivalent L1 virus-like-particle vaccine against infection with human papillomavirus types 16 and 18 in young women: an interim analysis of a phase III double-blind, randomised controlled trial. Lancet. 2007;369(9580):2161-70.

15. Louvanto K, Rintala MA, Syrjänen KJ, Grénman SE, Syrjänen SM. GenotypeSpecific Persistence of Genital Human Papillomavirus (HPV) Infections in Women Followed for 6 Years in the Finnish Family HPV Study. Journal of Infectious Diseases. 2010;202(3):436-44.

16. de Sanjose S, Quint WGV, Alemany L, Geraets DT, Klaustermeier JE, Lloveras B, et al. Human papillomavirus genotype attribution in invasive cervical cancer: a retrospective cross-sectional worldwide study. The Lancet Oncology. 2010;11 (11):1048-56. Available from http://www.sciencedirect.com/science/article/pii/ S1470204510702308. DOI http://dx.doi.org/10.1016/S1470-2045(10)70230-8.

17. Li N, Franceschi S, Howell-Jones R, Snijders PJ, Clifford GM. Human papillomavirus type distribution in 30,848 invasive cervical cancers worldwide: variation by geographical region, histological type and year of publication. Int J Cancer. 2011;128(4):927-35.

18. Resnick RM, Cornelissen MT, Wright DK, Eichinger GH, Fox HS, ter Schegget J, et al. Detection and typing of human papillomavirus in archival cervical cancer specimens by DNA amplification with consensus primers. J Nat Cancer Inst. 1990;82(18):1477-84.

19. Lee SH, Vigliotti VS, Vigliotti JS, Pappu S. Validation of human papillomavirus genotyping by signature DNA sequence analysis. BMC Clin Pathol. 2009;9:3.

20. Castellsague X, Diaz M, de Sanjose S, Munoz N, Herrero R, Franceschi S, et al. Worldwide human papillomavirus etiology of cervical adenocarcinoma and its cofactors: implications for screening and prevention. J Natl Cancer Inst. 2006:98:303-15.

21. Castellsague $X$, Klaustermeier J, Carrilho C, Albero G, Sacarlal J, Quint W, et al. Vaccine-related HPV genotypes in women with and without cervical cancer in Mozambique: Burden and potential for prevention. Int J Cancer. 2008;122:1901-4.

22. Louie KS, de Sanjose S, Mayaud P. Epidemiology and prevention of human papillomavirus and cervical cancer in sub-Saharan Africa: a comprehensive review. Tropical medicine \& international health : TM \& IH. 2009;14(10):1287-302.

23. Piras F, Piga M, De Montis A, Zannou A, Minerba L, Perra M, et al. Prevalence of human papillomavirus infection in women in Benin. West Africa Virology Journal. 2011;8(1):514. Available from http://www.virologyj. com/content/8/1/514

24. de Oliveira CM, Fregnani JH, Carvalho JP, Longatto-Filho A, Levi JE. Human papillomavirus genotypes distribution in 175 invasive cervical cancer cases from Brazil. BMC Cancer. 2013;13:357.

25. Giorgi Rossi P, Sideri M, Carozzi FM, Vocaturo A, Buonaguro FM, Tornesello $M L$, et al. HPV type distribution in invasive cervical cancers in Italy: pooled analysis of three large studies. Infectious Agents and Cancer. 2012;7(1):26.

26. Chinchai $T$, Chansaenroj J, Swangvaree $S$, Junyangdikul P, Poovorawan $Y$. Prevalence of human papillomavirus genotypes in cervical cancer. Int J Gynecol Cancer. 2012;22(6):1063-8.

27. Peralta-Rodriguez R, Romero-Morelos P, Villegas-Ruiz V, Mendoza-Rodriguez M, Taniguchi-Ponciano K, Gonzalez-Yebra B, et al. Prevalence of human papillomavirus in the cervical epithelium of Mexican women: meta-analysis. Infectious Agents and Cancer. 2012;7(1):34 
28. Haghshenas M, Golini-moghaddam T, Rafiei A, Emadeian O, Shykhpour A, Ashrafi GH. Prevalence and type distribution of high-risk human papillomavirus in patients with cervical cancer: a population-based study. Infectious Agents and Cancer. 2013;8(1):20.

29. Khan MJ, Castle PE, Lorincz AT, Wacholder S, Sherman M, Scott DR, et al. The elevated 10-year risk of cervical precancer and cancer in women with human papillomavirus (HPV) type 16 or 18 and the possible utility of typespecific HPV testing in clinical practice. J Natl Cancer Inst. 2005;97:1072-9.

30. Stevens MP, Garland SM, Tabrizi SN. Human papillomavirus genotyping using a modified linear array detection protocol. J Virol Methods. 2006;135 (1):124-6.

31. Thomas JO, Herrero R, Omigbodun AA, Ojemakinde K, Ajayi IO, Fawole A, et al. Prevalence of papillomavirus infection in women in Ibadan, Nigeria: a population-based study. Br J Cancer. 2004;90(3):638-45.

32. Garcia-Espinosa B, Nieto-Bona MP, Rueda S, Silva-Sanchez L, Piernas-Morales MC, Carro-Campos P, et al. Genotype distribution of cervical human papillomavirus DNA in women with cervical lesions in Bioko. Equatorial Guinea Diagnostic Pathology. 2009;4(1):31.

33. Smith JS, Lindsay L, Hoots B, Keys J, Franceschi S, Winer R, et al. Human papillomavirus type distribution in invasive cervical cancer and high-grade cervical lesions: a meta-analysis update. Int J Cancer. 2007;121(3):621-32.

34. Clifford GM, Smith JS, Plummer M, Munoz N, Franceschi S. Human papillomavirus types in invasive cervical cancer worldwide: a meta-analysis. Br J Cancer. 2003;88(1):63-73.

35. Alidjinou EK, Ebatetou-Ataboho E, Sane F, Moukassa D, Dewilde A, Hober D. Cervical samples dried on filter paper and dried vaginal tampons can be useful to investigate the circulation of high-risk HPV in Congo. J Clin Virol. 2013;57(2):161-4.

36. Giorgi Rossi P, Bisanzi S, Paganini I, Di lasi A, Angeloni C, Scalisi A, et al. Prevalence of HPV high and low risk types in cervical samples from the Italian general population: a population based study. BMC Infect Dis. 2010;10:214.

37. Okolo C, Franceschi S, Adewole I, Thomas J, Follen M, Snijders P, et al. Human papillomavirus infection in women with and without cervical cancer in Ibadan. Nigeria Infectious Agents and Cancer. 2010;5(1):24.

38. Khan S, Jaffer NN, Khan MN, Rai MA, Shafiq M, Ali A, et al. Human papillomavirus subtype 16 is common in Pakistaniwomen with cervical carcinoma. Int J Infect Dis. 2007;11:313-7.

39. WHO/ICO. Information Centre on HPV and Cervical Cancer (HPV Information Centre). Human Papillomavirus and Related Cancers in World. Summary Report 2010 [accessed on 2014-05-09]. 2010.

doi:10.1186/1471-2458-14-1320

Cite this article as: Boumba et al: Specific genotypes of human papillomavirus in 125 high-grade squamous lesions and invasive cervical cancer cases from Congolese women. BMC Public Health 2014 14:1320.

\section{Submit your next manuscript to BioMed Central and take full advantage of:}

- Convenient online submission

- Thorough peer review

- No space constraints or color figure charges

- Immediate publication on acceptance

- Inclusion in PubMed, CAS, Scopus and Google Scholar

- Research which is freely available for redistribution 